IZA DP No. 114

\title{
An Explanation of International Differences in Education and Workplace Training
}

Giorgio Brunello

Alfredo Medio

February 2000 


\title{
An Explanation of International Differences in Education and Workplace Training
}

\author{
Giorgio Brunello \\ University of Padova, FEEM, IZA, Bonn \\ Alfredo Medio \\ University of Venice \\ Discussion Paper No. 114 \\ February 2000 \\ IZA \\ P.O. Box 7240 \\ D-53072 Bonn \\ Germany \\ Tel.: +49-228-3894-0 \\ Fax: +49-228-3894-210 \\ Email: iza@iza.org
}

This Discussion Paper is issued within the framework of IZA's research area General Labor Economics. Any opinions expressed here are those of the author(s) and not those of the institute. Research disseminated by IZA may include views on policy, but the institute itself takes no institutional policy positions.

The Institute for the Study of Labor (IZA) in Bonn is a local and virtual international research center and a place of communication between science, politics and business. IZA is an independent, nonprofit limited liability company (Gesellschaft mit beschränkter Haftung) supported by the Deutsche Post AG. The center is associated with the University of Bonn and offers a stimulating research environment through its research networks, research support, and visitors and doctoral programs. IZA engages in (i) original and internationally competitive research in all fields of labor economics, (ii) development of policy concepts, and (iii) dissemination of research results and concepts to the interested public. The current research program deals with (1) mobility and flexibility of labor markets, (2) internationalization of labor markets and European integration, (3) the welfare state and labor markets, (4) labor markets in transition, (5) the future of work, (6) project evaluation and (7) general labor economics.

IZA Discussion Papers often represent preliminary work and are circulated to encourage discussion. Citation of such a paper should account for its provisional character. 


\section{ABSTRACT}

\section{An Explanation of International Differences in Education and Workplace Training*}

We develop a simple search equilibrium model of workplace training and education based on two features. First, investment in education improves job-related learning skills and reduces training costs burdened by firms. Second, firms with vacant skilled job slots can choose between recruitment from the market and training. Compared to Germany and Japan, the US has both a higher inflow rate into unemployment and a higher efficiency of the matching process. While the combined effort of these differences on the share of educated labor is ambiguous, the effect on the percentage of firms undertaking workplace training is to unambiguously reduce it.

JEL Classification: J24, J31

Keywords: Education, workplace training

Giorgio Brunello

Department of Economics

University of Padua

Via del Santo 33

35100 Padua

Italy

Email: brunello@decon.unipd.it

\footnotetext{
We are grateful to Francois Bourguignon, to an anonymous referee, and to audiences in Athens, Deakin, Essex, the European University Institute, Melbourne, Venice and WZB Berlin for comments and suggestions. The usual caveats apply.
} 


\section{Introduction}

In the empirical literature on education and training it is often remarked that the US has at least as high levels of schooling but less enterprise training than Germany or Japan (see Lynch (1994)). Educational attainment in 1992, measured by the percentage of individuals aged between 25 and 44 who have attained at least upper secondary education, was well above $80 \%$ in these three countries, and higher than average attainment in the OECD area (See OECD (1995)). If we restrict our definition of attainment to tertiary education, the US does better than Japan and Germany, with about 31 percent of individuals aged 25 to 64 having completed tertiary education, compared to $23.5 \%$ in Japan and to $22 \%$ in Germany.

The US, however, does not perform as well when workplace training is concerned. The view that US firms under-invest in their workers when compared to Japan and Germany is presented by Bishop (1993) and Lynch (1993). According to Freeman (1995), "..the US has a weak in-firm training system.... The experience of Germany and Japan, the exemplars of in-firm training, shows that considerable institutional structure is needed to induce firms to provide training to workers..." $(1995$, p.7).

International comparisons of training data are difficult because of the poor comparability of available data. The evidence, however, supports this view. According to a recent OECD study, for instance, the incidence of in-house training for workers with less than 1 year of tenure in the early 1990s was close to 80 percent in Japan and less than 10 percent in the US (OECD (1993)). This difference is less dramatic but still remarkable when informal training in the US is accounted for. In this case, the incidence of in-house training is close to 90 percent among large Japanese firms and close to 50 percent among large American firms (see Brown et al (1997)).

Economic explanations of these international differences have focused either on educational attainment or on workplace training. Blinder and Krueger (1991), for instance, attribute the relative lack of workplace training in the US to high turnover. In a similar fashion, Acemoglu and Pischke (1999) present a model that features multiple equilibria and stress the trade off between training and quits.

Other contributions have treated education and training as a single decision taken by individuals. Saint Paul (1996), for instance, presents an OLG model with rigid real wages where the young generation decides whether to invest in (general) human capital by investing in education. Snower (1995) develops a search equilibrium model in the tradition of Diamond and Pissarides whereby firms supply skilled vacancies and workers invest in skills by acquiring education. Finally, Laing, Palivos and Wang (1995) have an endogenous growth model where educated workers acquire human capital on the job at a faster rate than non-educated workers. The acquisition process, however, is exogenously determined ${ }^{1}$.

\footnotetext{
${ }^{1}$ Other relevant contributions include Acemoglu (1996) and Redding (1996).
} 
Treating education and training as a single decision is satisfactory when the focus is on vocational training provided by schools, but less satisfactory when we consider that a substantial amount of training in modern economies is provided by firms ${ }^{2}$. When workplace training is important, the decision to invest in education and the decision to train should be treated as separate decisions, that involve both workers and firms.

This paper presents a simple explanation of the stylized differences in education and workplace training in the US, Germany and Japan that is based on the separation of the decision to invest in education, taken by workers, from the decision to invest in training, taken by firms. For this purpose, we treat vocational training, that is acquired in the classroom, as education, and in-house training, that is acquired in the workplace, as training ${ }^{3}$. We develop a simple search equilibrium model of workplace training and education based on three features. First, investment in education improves job-related learning skills and reduces training costs born by firms (See Rosen (1976)) ${ }^{4}$. Second, firms with vacant skilled job slots can choose between recruitment from the market and training. This choice depends both on training and on recruitment costs. Third, training positions are filled by educated individuals because the complementarity of education and training makes educated workers cheaper to train. We emphasize training as an option that saves on recruitment costs, in line with recent theoretical work and with the existing evidence that firms are willing to bear part or all of the training costs even when skills are general (Barron, Black and Lowenstein (1989), Stevens (1994), Franz-Soskice (1995), Brunello (1996) and Acemoglu and Pischke (1999)).

We show that, ceteris paribus, a higher efficiency of the matching process is associated, in equilibrium, to less workplace training. A higher matching efficiency, however, does not necessarily imply a smaller wage differential between skilled and unskilled jobs. Therefore, a more compressed wage structure is not required to induce more firms to train ${ }^{5}$. We also show that, unless additional assumptions involving the wage structure and the probability of finding a training position are introduced, we cannot tell unambiguously whether higher matching

\footnotetext{
${ }^{2}$ The importance of workplace training is widely recognized (see OECD (1991), Lynch (1994) and the references therein). In his well known job competition model, Lester Thurow (1975) argued that, even when skills are fully transferrable, education is unlikely to produce marketable skills without any job experience.

${ }^{3}$ This distinction is somewhat artificial, because training schemes often combine training in the classroom with training in the workplace. A typical example is the German apprenticeship system. In this paper, we classify apprenticeships are training.

${ }^{4}$ The OECD report summarizes the empirical evidence as follows..."Education and postschool training seem to be complements. One implication is that, on average, less formal schooling probably leads to more limited training opportunities and possibilities for augmenting human capital.."((1991), p.152). According to Thurow, employers rank workers in accordance with their background characteristics, which they use as indirect indicators of the costs necessary to produce the standard work performance. Education is perhaps the most relevant background characteristic and is key to access to skilled and better paid jobs.

${ }^{5}$ Acemoglu and Pischke (1999) show that wage compression is required to induce firms to train. Their definition of wage compression, however, refers to the wages of the same worker when trained and untrained, rather than to the wage differential between skilled and unskilled employees.
} 
efficiency leads to more or to less schooling.

In a similar fashion, a higher (exogenous) inflow rate into unemployment is associated, in equilibrium, to less workplace training. As in the case of matching efficiency, the relationship between the inflow rate, the wage structure and the equilibrium share of educated individuals is ambiguous.

Compared to Germany and Japan, the US combines a higher inflow rate into unemployment with a higher efficiency of the matching process to produce a higher outflow rate from the unemployment pool. While the joint effect of these differences in matching efficiency and in the inflow rate on the share of educated labor is ambiguous, a key finding of the paper is that they unambiguously reduce the percentage of firms undertaking workplace training.

The material of the paper is organized as follows. Section 2 presents the model and Section 3 discusses the main results and concludes.

\section{The Model}

\subsection{Setup}

Consider a prototype economy populated by a large number of risk neutral workers and firms. Each firm in this economy can choose between two technologies. With the first technology, a firm produces output by filling a skilled job slot. With the second technology, output is produced by filling an unskilled job slot. With one worker per firm, the number of firms is equal to the number of employed workers in skilled and unskilled jobs. Skills are general and we assume that the output produced in an unskilled job is lower than output produced in a skilled job slot. During each period of time, a fraction $s$ of filled job matches between workers and firms dissolve because of exogenous quits. This is equivalent to saying that a fraction of firms ends up with unfilled job positions ${ }^{6}$. We rule out endogenous turnover by assuming that the wages paid to skilled and unskilled employees do not vary among firms ${ }^{7}$.

While unskilled jobs can only be filled by trading in the market (matching), skilled jobs can be filled either by trading or by training. Education is useful in this setup because it improves the ability to learn skills, thereby reducing training costs (Rosen (1976, p.S47). Since educated workers have lower training costs than non educated workers, when the supply of educated labor market entrants is sufficient firms prefer to train educated to non educated workers.

Hence, education is a ticket to skilled and better paid jobs ${ }^{8}$. If not used to learn a skill, however, the relative advantage of being educated rapidly decays.

\footnotetext{
${ }^{6}$ Firms with unfilled job slots can switch costlessly from one technology to the other but jobs cannot be profitably held by either type of worker. For simplicity, the separation rate $s$ is assumed not to vary with the type of job.

${ }^{7}$ This assumption is briefly discussed in footnote 15.

8 "..private firms are extremely reluctant to invest heavily in training low skilled workers.." (OECD (1991), p.31). According to the European Commission. "..there is increasing evidence that how well they are educated is a key determinant of the ability of workers to acquire new skills and to adapt to changes in technology and methods of working" (European Commission (1992).
} 
We capture this obsolescence process by assuming that educated labor market entrants who remain unemployed for a period of time lose their relative advantage in skill acquisition and are treated by firms as equivalent to individuals without education ${ }^{9}$.

Trading is time consuming and implies positive matching costs but saves training costs, because hired employees already have the required general skills. Training, on the other hand, requires only training costs. These costs vary across firms. In real life, training also requires time. Our assumption that training takes place instantaneously at a positive cost is clearly a simplification, that we find useful to sharpen the trade-off with matching. Heterogeneous training costs imply that only some firms adopting the technology with a skilled job slot will use training as a way of filling up their vacant slot. Let the fraction of firms using training rather than hiring by $\sigma, 0 \leq \sigma \leq 1$.

We focus our analysis exclusively upon the steady state equilibrium, and we characterize it by the absence of productivity growth and by a constant labor force $^{10}$. The labor market is segmented into skilled and unskilled. In each period of time, the constant labor force $L$ is composed of $L_{E}$ educated individuals and of $L-L_{E}$ workers without education. In this paper, by education we mean upper secondary or higher education, inclusive of off-the-job vocational training, and by lack of education we mean compulsory education ${ }^{11}$. As mentioned above, all educated workers have to be trained in order to become skilled employees.

In the steady state equilibrium, the share of educated individuals in the labor force, $L_{E} / L$, is constant and equal to $\eta$, where $0 \leq \eta \leq 1$. Educated workers are either employed in a skilled job $\left(N_{2}\right)$ or unemployed after experiencing a skilled job $\left(U N_{2}\right)$ or unemployed labor market entrants without any training $(U E)$. Here, the subscript 2 refers to skilled labor and the subscript 1 to unskilled labor. The latter group consists of new labor market entrants, who have just completed their education. In the steady state, the size of this group depends on demographic factors such as the percentage of young individuals in the educated labor force. Let $\zeta=\frac{U E}{L_{E}}$ be this percentage ${ }^{12}$. Workers without education join the unskilled labor market and can be either employed $\left(N_{1}\right)$ or unemployed $\left(U N_{1}\right)$. Educated labor market entrants who find a training position in a firm join the skilled labor market. Those who could not find a training position lose the relative advantage in skill acquisition provided by education and become at the end of the period observationally equivalent to uneducated workers. They join the unskilled labor market.

All firms operating in this economy share the same matching technology. Assuming a Cobb Douglas matching function, with the number of matches increasing both in the number of skilled vacancies and in the number of skilled

\footnotetext{
${ }^{9}$ Similar effects are discussed in the literature on "over-education". See for instance Sicherman (1991).

${ }^{10}$ We refer the reader to Brunello and Medio (1996) for the analysis of the existence and stability of equilibria in a similar, but more complex, setup.

${ }^{11}$ Since education is not equivalent to skill, because of the need of additional training, the allocation of individuals to the educated and the non educated group is not equivalent to the allocation to skilled and unskilled labor.

${ }^{12}$ This implies that the share of skilled labor in the labor force is $(1-\zeta) \eta$.
} 
unemployed workers, the ratio of matches to skilled vacancies $q_{2}$ can be written as

$$
q_{2}=m_{2} \theta_{2}^{-k_{2}}
$$

where $k_{2}<1, \theta_{2}$ is the ratio of skilled vacancies to skilled unemployment and $m_{2}$ measures the efficiency of the matching technology (see Blanchard and Diamond (1989)). With a change of subscripts, a similar expression holds for the ratio of matches to unskilled vacancies, $q_{1}$. We also define the outflow rate from skilled unemployment as the ratio between matches $x_{2}$ and skilled unemployment $U N_{2}$. This outflow is equal to $q_{2} \theta_{2}=m_{2} \theta_{2}^{1-k_{2}}$.

Firms differ in their training costs. We assume that the training cost is a random variable $\Upsilon$ taking values in the positive interval $\tau \in\left(\tau_{1}, T\right)$, with cumulative distribution function $G(\tau)=\operatorname{Prob}(\Upsilon \leq \tau)$.

\subsection{Flows}

With an exogenous separation rate $s$, in each period of time there are $s N_{2}$ skilled employees who move from skilled employment into the unemployment pool $U N_{2}$ and $x_{2}$ new matches of skilled workers with vacant skilled jobs. Matches $x_{2}$ are equal to $x_{2}=q_{2} \theta_{2} U N_{2}$.

Skilled workers in the unemployment pool $U N_{2}$ either look for a new match or retire from the labor market ${ }^{13}$. Educated new entrants, who by definition have received no training, flow into the stock $U E$ at a constant rate per period. Letting $p$ be the probability of finding a training job during a period of time, $p U E$ new entrants move each period from unemployment to employment and the rest joins the unskilled labor market at the end of the period.

With $\sigma$ firms filling their skilled vacancies by training educated labor market entrants, and using small letters for rates, the flow rate pue is also equal to

$$
p u e=p \zeta=\sigma s n_{2}
$$

where $n_{2}=\frac{N_{2}}{L_{E}}$ is the steady state employment rate of educated labor in skilled jobs. Since a percentage $(1-\sigma)$ of firms fill their skilled vacancies by hiring skilled employees, $n_{2}$ is given by

$$
q_{2} \theta_{2} u n_{2}=(1-\sigma) s n_{2}
$$

Next, the unemployment rate of educated labor, $u_{E}=\left(u n_{2}+u e\right)$, is given simply by

$$
u n_{2}=1-\zeta-n_{2}
$$

Given $\theta_{2}$ and $\sigma$, Eqs. (3) and (4) are sufficient to determine both unemployment and employment of skilled labor in the steady state equilibrium. In

\footnotetext{
${ }^{13}$ In this paper retirement is driven by exogenous factors and can only occur from the (skilled and unskilled) unemployment pool.
} 
particular, the equilibrium unemployment rate $u_{E}$ is given by

$$
u_{E}=\frac{s(1-\sigma)+\zeta q_{2} \theta_{2}}{s(1-\sigma)+q_{2} \theta_{2}}
$$

Using Eqs. (2), (4) and (5) we also obtain that the probability of finding a training slot is equal to

$$
p=\frac{s \sigma(1-\zeta) q_{2} \theta_{2}}{\zeta\left[s(1-\sigma)+q_{2} \theta_{2}\right]}
$$

Equilibrium unemployment $u_{E}$ is a decreasing function both of $\sigma$ and of $q_{2} \theta_{2}$. It tends to $\zeta$ when $\sigma$ tends to 1 and to $\frac{s+\zeta q_{2} \theta_{2}}{s+q_{2} \theta_{2}}$ when $\sigma$ tends to zero. Moreover, the probability $p$ tends to zero as $\sigma$ goes to zero and to $\frac{s(1-\zeta)}{\zeta}$ as $\sigma$ goes to 1 . Therefore, to guarantee that $p \in(0,1)$ we have to assume that $\zeta \geq \frac{s}{1-s}$. This is equivalent to assuming that there is always a sufficient supply of educated labor market entrants to fill the skilled vacancies generated by exogenous job separations. We briefly come back to this point later on in the paper.

Finally, notice that the probability $p$ increases both with $\sigma$ and with $q_{2} \theta_{2}$. In the former case, this happens because the percentage of training firms increases. In the latter case, the equilibrium employment rate $n_{2}$ increases. Therefore, the number of skilled vacancies generated by exogenous separations must also increase.

\subsection{Matching and Training}

Vacant slots for skilled jobs can be filled either from the market or by training an educated but unskilled individual. Define $V_{2}$ and $T_{2 j}$ respectively as the asset value of a skilled vacancy filled from the market and the asset value of a skilled vacancy filled by training. Firms do not differ in their matching technologies, but have firm-specific training costs. Hence, we use the firm index $j$ for $T_{2}$ but not for $V_{2}$.

When a vacancy is filled from the market, its expected return is given by

$$
r V_{2}=-1+q_{2}\left(J_{2}-V_{2}\right)
$$

where $r$ is the rate of interest, exogenous to the model, $J_{2}$ is the asset value of a filled skilled job, the cost of keeping a skilled vacancy unfilled is normalized to 1 and $\left(J_{2}-V_{2}\right)$ is the net return from the change of state, that occurs at the rate $q_{2}$. In the absence of firm specific matching costs, all profit opportunities from new vacancies are exploited in equilibrium and $V_{2}=0$ (see Pissarides (1990)). This implies that $J_{2}=\frac{1}{q_{2}}$.

Since training does not require matching costs, each training position can be filled immediately. Assume that the cost of training be borne entirely by firms, as discussed in detail by Acemoglu and Pischke (1999). The asset value of a training position is given by

$$
T_{2 j}=J_{2}-\tau_{j}
$$


where $\tau_{j}$ is the idiosyncratic training cost. Firms decide whether to train an educated labor market entrant by comparing the asset value from training with the asset value from matching. Since training costs vary across firms, not all firms engaged in training make zero profits. Define the marginal firm $c$ as the firm that is just indifferent between training and matching. For this firm, the asset value $T_{2 c}$ is equal to zero in the steady state equilibrium. Firms with positive asset values of training $\left(T_{2 j}>0\right)$ prefer to fill their skilled vacancies by opening training positions and firms with negative asset values of training $\left(T_{2 j}<0\right)$ prefer matching to training.

Using the zero profit condition on skilled vacancies $\left(V_{2}=0\right)$, we obtain that the training cost associated to the marginal firm is

$$
\tau_{c}=\frac{1}{q_{2}}
$$

Since firms differ only in their training cost $\tau$, the $\sigma$ firms which select training have training costs $\tau_{j} \leq \tau_{c}$. Hence, $\sigma=G\left(\tau_{c}\right)$. As the ratio between matches and skilled vacancies $q_{2}$ goes to zero, the training cost $\tau_{c}$ goes to infinity and $G\left(\tau_{c}\right)$ goes to 1 . On the other hand, when the matching probability $q_{2}$ is equal to 1 the marginal training $\operatorname{cost} \tau_{c}$ is also equal to 1 . In this case, if the minimum training cost $\tau_{1}$ is less than 1 , the percentage of training firms is equal to $\sigma=G(1)>0$, and there will always be some firms filling their skilled vacancies with training rather than with matching. Henceforth, we shall restrict our analysis to economies for which this assumption holds.

Because the critical cost $\tau_{c}$ depends upon the matching probability $q_{2}$, that depends on $\theta_{2}$, we need to determine the equilibrium ratio of skilled vacancies to skilled unemployment. We start from the relation $J_{2}=\frac{1}{q_{2}}$, that equates the asset value of a filled skilled job with the (expected) duration of a skilled vacancy. The return to a filled skilled job is equal to the current profit $y_{2}-w_{2}$, where $y_{2}$ is output per skilled worker and $w_{2}$ is the skilled wage, plus the expected return from a change of state, that occurs with probability $s$.

When a skilled job turns vacant, it can be filled either by matching or by training. Consider the marginal firm $c$. For this firm, the asset value of a vacant skilled job is zero and the return from a filled skilled job is

$$
r J_{2}=y_{2}-w_{2}-s J_{2}
$$

This is also the return expected by firms that fill their skilled vacancies by matching. Notice that firms with training costs lower than $\tau_{c}$, which fill their vacancies by training, can expect higher returns from filled skilled jobs, because the value of their skilled vacancies is strictly positive $\left(T_{2 j}>0\right)$. These rents are associated to the presence of firm specific training costs.

Wage determination requires that we define both the return from skilled employment and the return from skilled unemployment. Since wages do not vary among firms by assumption, we can focus on the marginal firm and write 


$$
r E_{2}=w_{2}+s\left(U_{2}-E_{2}\right)
$$

where $E_{2}$ is the asset value of skilled employment.

As mentioned above, skilled workers in the unemployment pool can either remain unemployed, find a new skilled match or retire from the labor market. Let income from current unemployment be equal to zero and assume that the asset value of retirement be equal to the asset value of unemployment ${ }^{14}$. Then the return from unemployment is

$$
r U_{2}=q_{2} \theta_{2}\left(E_{2}-U_{2}\right)
$$

where $U_{2}$ is the asset value of skilled unemployment.

Wages are set by Nash bargaining between the parties involved in the match, and the net return from the match is $E_{2}-U_{2}$ for the worker and $J_{2}$ for the (marginal) firm (see Pissarides (1990)). Let the parties share the same bargaining power. Hence, the relative bargaining power of skilled labor, $\beta_{2}$, is equal to $\frac{1}{2}$. These assumptions ensure that, in the steady state equilibrium, the skilled wage is equal to $w_{2}=\frac{1}{2}\left(y_{2}+\theta_{2}\right)^{15}$ and that the vacancy-unemployment ratio $\theta_{2}$ be given by

$$
\frac{y_{2}-\theta_{2}}{2(r+s)}=\frac{\theta_{2}^{k_{2}}}{m_{2}}
$$

Total differentiation of Eq. (13) shows that $\theta_{2}$ is increasing in $m_{2}$ and decreasing in $s^{16}$. We can use these results to state the following

Remark 1 An increase in the efficiency of the matching technology $m_{2}$ reduces the share $\sigma$ of firms undertaking training because it increases the ratio of skilled vacancies to skilled unemployment $\theta_{2}$.

Notice that $\sigma$ increases with $\tau_{c}$. Moreover, $\tau_{c}$ decreases with $q_{2}$, the probability of filling a skilled vacancy from the market. Since $\frac{\partial q_{2}}{\partial m_{2}}$ is positive because

\footnotetext{
${ }^{14}$ This is consistent with our assumption that retirement is driven by exogenous factors.

${ }^{15}$ Relaxing the assumption that firms pay the same wage to their skilled (or unskilled) employees does not affect the outcome both for the marginal firm and for firms using matching rather than training to fill skilled vacancies. In principle it could affect the wages paid by firms with positive asset values of training $\left(T_{2 j}>0\right)$, because these firms could split these rents with their employees. We find this outcome unlikely in the presence of general and fully transferrable skills.

${ }^{16}$ Under the postulated assumptions on the parameters, Eq. (13) has a unique positive solution for $\theta_{2}$. This can be seen by re-writing Eq. (13) as

$$
f_{1}\left(\theta_{2}\right)=f_{2}\left(\theta_{2}\right)
$$

where $f_{1}\left(\theta_{2}\right)=\frac{y_{2}-\theta_{2}}{2(r+s)}$ and $f_{2}\left(\theta_{2}\right)=\frac{\theta_{2}^{k_{2}}}{m_{2}}$. It is easy to verify geometrically that the two functions have a unique intersection in the positive orthant.
} 
of Eq.(13), the share of training firms declines when efficiency $m_{2}$ increases ${ }^{17}$. The economic intuition is simple. An improvement in the matching technology makes it easier for firms to fill skilled vacancies directly from the market, thus reducing the incentive to train unskilled educated labor.

Remark 2 For any given level of $m_{2}$, an increase in the exogenous inflow rate into unemployment s reduces $\theta_{2}$, thus reducing the share $\sigma$ of firms undertaking training.

This follows from the fact that both $\frac{\partial q_{2}}{\partial \theta_{2}}$ and $\frac{\partial \theta_{2}}{\partial s}$ are negative. Firms that pay for training need to recover their costs. When the inflow rate $s$ increases, the time period during which firms can recover these costs is shorter ${ }^{18}$. This reduces the incentive that firms have to open skilled vacancies. With relatively fewer skilled vacancies, the probability of filling a vacancy from the market $q_{2}$ increases and the proportion of training firms falls.

To conclude this section, an important question is whether individuals with no education can underbid educated workers and obtain a training position. With a sufficient supply of educated workers, the answer is negative for the following two reasons: first, individuals with no education require higher training costs. Second, unless they can commit to work at a wage lower than $w_{2}$, workers with no education who can find a skilled job will bid their wage up to $w_{2}$ after firms have sunk their training costs ${ }^{19}$.

\subsection{Investing in Education}

Next, we turn to the individual decision to invest in education. It is simplest to think of the investment in education as a time consuming activity that occurs before entering the labor market. In what follows, we assume that working individuals do not go back to education, that is fully acquired before any labor market activity is started. Furthermore, educated individuals are assumed to enter the labor market as unemployed workers without fully developed skills and to queue for a training job slot. Similarly, individuals with no education are assumed to enter the labor market via the pool of unskilled unemployment.

Thus education per se is a condition but does not guarantee employment in a skilled job slot. Educated workers need also workplace training. Let $I$ be the asset value of queueing for a training position. Access to the queue is limited to educated labor and requires that individuals pay the education $\operatorname{cost} \xi_{i}$, with $0 \leq \xi_{i} \leq \xi_{M}$, that varies among individuals. The net return from queueing as an unemployed educated new entrant, $r I$, is equal to the (expected)

${ }^{17}$ Using Eqs. (1) and (13) we can show that

$$
\frac{\partial \ln q_{2}}{\partial \ln m_{2}}=1-\frac{k_{2}}{k_{2}+\frac{m_{2}}{2(r+s) \theta_{2}^{k_{2}-1}}}>0
$$

${ }^{18}$ See Acemoglu (1997).

${ }^{19}$ See the discussion of the hold up problem in Malcolmson (1997). 
return from finding a training position and joining the skilled labor market, that occurs with probability $p$, plus the (expected) return from access to the unskilled labor market, that takes place after a spell as an unemployed new entrant and occurs with probability $1-p$, minus the investment cost $\xi$. Employment in a skilled job yields $E_{2}{ }^{20}$. Entry in the unskilled labor market from the pool of unemployed educated new entrants yields $U_{1}$, the asset value of unemployment as an unskilled individual. Hence, $r I=p\left(E_{2}-I\right)+(1-p)\left[U_{1}-I\right]-\xi$.

The costs of investing in education must also include the foregone earnings from immediate access to the unskilled labor market as a non educated worker, $r U_{1}$. The definitions of the asset values for non educated labor, including $U_{1}$, are similar to equations (10)-(12), with the exception that we assume that unskilled workers have less bargaining power than skilled workers. Letting $\beta_{1}$ be the relative bargaining power of unskilled labor, this is equivalent to assuming that $\beta_{1}<\frac{1}{2}^{21}$.

In the steady state equilibrium, the share of educated individuals is determined by the marginal investment decision, undertaken by the individual who is just indifferent between investing and not investing. The critical value of the cost of education, $\xi^{*}$, that yields indifference between investing and not investing is

$$
\xi^{*}=p\left[E_{2}-U_{1}\right]-r U_{1}
$$

where the probability $p$ is determined by Eq. (6). As discussed above, the probability of finding a training position depends positively both on $\sigma$, the percentage of firms undertaking training, and on the outflow rate from unemployment $q_{2} \theta_{2}$. Hence, an increase in the efficiency of the matching technology $m_{2}$ has two opposite effects on $p$. First, it increases it because it raises the employment rate via a higher outflow rate. Second, it reduces it because the percentage of training firms $\sigma$ declines (see Remark 2.1). Thus the overall effect cannot be signed. On the other hand, an increase in the separation rate $s$ reduces the probability $p$, because both $\sigma$ and $q_{2} \theta_{2}$ decline.

The wages of skilled workers have already been discussed. The wage paid to unskilled labor is determined in a similar fashion, by solving a standard cooperative Nash bargaining game between the parties. In this case, we have that $w_{1}=\beta_{1}\left(y_{1}+\theta_{1}\right)$. Consequently, the wage structure, defined as the differential between the skilled and the unskilled wage, is equal to

\footnotetext{
${ }^{20}$ We are assuming that income during training is zero. Since output during training is also assumed to be zero, the cost of training is born entirely by the firm.

${ }^{21}$ In the steady state equilibrium the unskilled unemployment rate is determined as follows: first, there must be sufficient outflows from the non educated labor force to compensate the inflows by new entrants and by educated individuals who have lost their relative advantage because of unemployment. Second, exogenous separations of unskilled workers must be equal to inflows from unskilled unemployment, and the equilibrium unskilled unemployment rate is$$
u_{1}=\frac{s}{s+q_{1} \theta_{1}}
$$ 


$$
\Delta=w_{2}-w_{1}=\left(\frac{1}{2} y_{2}-\beta_{1} y_{1}\right)+\left(\frac{1}{2} \theta_{2}-\beta_{1} \theta_{1}\right)
$$

When there are enough new educated entrants to fill the available training positions, workers with no education are trapped in the unskilled labor market. Using the asset equations for unskilled labor and the definition of the wage $w_{1}$ resulting from Nash bargaining, the vacancy-unemployment ratio for unskilled labor $\theta_{1}$ is determined by

$$
\frac{y_{1}\left(1-\beta_{1}\right)-\beta_{1} \theta_{1}}{(r+s)}=\frac{\theta_{1}^{k_{1}}}{m_{1}}
$$

Assuming that the cost of education $\xi$ has a uniform distribution and that individuals are not credit constrained, the steady state share of educated workers in the labor force $\eta=\frac{\xi^{*}}{\xi_{M}}$ is given by ${ }^{22}$

$$
\eta=p\left[\frac{\theta_{2}}{r}-\frac{\beta_{1}}{1-\beta_{1}} \frac{\theta_{1}}{r}+\frac{y_{2}-\theta_{2}}{2(r+s)}\right]-\frac{\beta_{1} \theta_{1}}{1-\beta_{1}}
$$

We can use Eqs. (6), (13) and (17) to state the following

Remark 3 An increase in the matching efficiency $m_{h}(h=1,2)$ has ambiguous effects on the equilibrium share of educated labor $\eta$, depending on the relative size of the effects on the probability $p$ and on the vacancy-unemployment ratios $\theta_{h}(h=1,2)$.

As we have seen above, an increase in the efficiency of the matching process has ambiguous effects on the probability $p$ of finding a training position. Moreover, a higher $m_{h}(h=1,2)$ increases both $\theta_{1}$ and $\theta_{2}$, with ambiguous effects on $\eta$.

Remark 4 An increase in the efficiency of the matching process $m_{h}(h=1,2)$ makes the wage structure $\Delta$ less compressed only when $\beta_{1}=0$.

If we interpret an increase in the efficiency of matching as a reduction of labor market imperfections, as done by Acemoglu and Pischke (1999), this reduction leads to a smaller share of firms undertaking training without necessarily increasing the wage differential between skilled and unskilled jobs. To see this, notice that an increase in matching efficiency increases both $\theta_{1}$ and $\theta_{2}$, that enter with opposite signs in Eq. (15). Hence, a less compressed wage structure is not required to induce firms to invest more in training. Moreover, and contrary to Acemoglu and Pischke (1999), a reduction in labor market imperfections that reduces training need not necessarily increase the percentage of individuals investing in education.

${ }^{22}$ Nash bargaining, $J_{2}=\frac{1}{q_{2}}$ and $V_{2}=0$ yield $E_{2}=U_{2}+\frac{1}{q_{2}}$. Hence, $E_{2}-U_{1}=U_{2}-U_{1}+\frac{1}{q_{2}}$. 
Remark 5 When the relative bargaining power of unskilled workers $\beta_{1}$ is equal to zero, an increase in the exogenous inflow rate s reduces the equilibrium share of educated labor $\eta$.

Compared to the previous case, a higher inflow rate into unemployment reduces both the probability $p$ and $\theta_{2}$, because the profitability of skilled vacancies declines.

To conclude this section, we briefly consider the case of limited supply of educated new entrants, that we have excluded at the start by assuming that $\zeta \geq \frac{s}{1-s}$. In this case, training firms need to hire workers without education for training. Assuming that this flow originates from the stock of unemployed labor without education, there are two major changes with respect to the case of sufficient supply. First, the probability that an educated new entrant finds a training job is now equal to 1 . Second, the net return from investing in education declines, because a training position and a skilled job can be obtained even without education. These changes imply that the equilibrium share of educated workers in the population is lower. The equilibrium percentage of training firms is also affected. To see why, consider two things. First, the equilibrium vacancy unemployment ratio for skilled jobs does not vary. Hence, the marginal training $\operatorname{cost} \tau_{c}$ also remains unchanged. Second, firms that were willing to train because their cost of training an educated worker was lower than $\tau_{c}$ could be unwilling to train a non educated worker at a much higher cost.

\section{Discussion and Conclusions}

Two important parameters in the model described above are $m_{h}(h=1,2)$, the efficiency of the matching process, and $s$, the exogenous inflow rate from employment to unemployment. Table 1 reports estimates of the outflow rates from employment and unemployment in the US, Germany and Japan, drawn from Burda and Wyplosz (1993).

This table shows that unemployment outflow rates are substantially higher in the US than in Germany or Japan. Employment outflow rates are also highest in the US, but the difference with Germany is rather small. Ceteris paribus, the higher the unemployment outflow rate, the lower unemployment duration. Hence, the table also shows that unemployment duration is lower in the US than in Germany and Japan. While these international differences refer to aggregate labor markets, there are reasons to believe that they apply also when we disaggregate by education. According to Layard et al (1991), for instance, the average duration of unemployment in the US is about the same for professional and managerial jobs, that are filled mainly by the highly educated, and for manual jobs, that are taken by the less educated ${ }^{23}$.

In our model, the outflow rate from unemployment is equal to $q_{h} \theta_{h}(h=$ $1,2)$. This rate is an increasing function of the efficiency of matching $m_{h}$ and a

\footnotetext{
${ }^{23}$ See Layard et al (1991), page 291.
} 
decreasing function of the inflow rate $s$. Therefore, with other things unchanged, a higher outflow rate can be consistent with a higher inflow rate $s$ only if the efficiency of matching $m_{h}$ is higher.

A key implication of our model is that the combination of a more efficient matching process with a higher separation rate reduces the proportion $\sigma$ of firms undertaking training. Thus, this proportion should be lower in the US, that has both a higher matching efficiency and a high inflow rate into unemployment. Another key implication is that the joint effect of a higher matching efficiency $m_{h}$ and of a higher separation rate $s$ on the share of educated individuals $\eta$ is ambiguous, even when $\beta_{1}$ is equal to zero. Depending on the relative size of these increases, and on the relative bargaining power of unskilled labor, the share of educated labor can increase, decrease or remain unchanged. Hence, it is quite possible for economies that differ only in the values of $m_{h}$ and $s$ to have significantly different levels of workplace training and similar levels of educational attainment, as documented in the case of the US, Germany and Japan. 
Table 1. Unemployment and employment outflows. 1987

\begin{tabular}{lcc}
\hline \hline & UE/U & EU/E \\
\hline \hline US & 2.43 & 0.26 \\
Germany & 1.46 & 0.21 \\
Japan & 1.16 & 0.09 \\
\hline \hline
\end{tabular}

Note: the numbers in the table are ratios of average annual flows over average stocks. Stocks refer to the condition of origin of the flow. UE: flows from unemployment to employment; EU: flows from employment to unemployment; $\mathrm{U}$ : unemployment; E: employment. 


\section{References}

[1] Acemoglu,D. (1996), A Microfoundation for Social Increasing Returns in Human Capital Accumulation, Quarterly Journal of Economics, 111, 779804 .

[2] Acemoglu, D. and Pischke, J. (1998), Why do firms train? Thory and evidence, Quarterly Journal of Economics, 110, 2, 355-81.

[3] Acemoglu, D. (1997), Training and Innovation in an Imperfect Labor Market, Review of Economic Studies, 64, 3, 445-64.

[4] Acemoglu, D. and Pischke, J. (1999), The Structure of Wages and Investment in General Training, Journal of Political Economy, 107, 3, 539-72.

[5] Barron, J., Black, D. and Lowenstein, M., (1989), Job matching and onthe-job training, Journal of Labor Economics, 1-19.

[6] Bishop, J., (1993), Underinvesting in Employer Training: A Mandate to Spend?, Human Resource Development Quarterly, 4, 3, 223-241.

[7] Blanchard, O. and Diamond, P. (1989), The Beveridge Curve, Brookings Papers on Economic Activity, 1.

[8] Blinder, A. and Krueger, A. (1991), International differences in turnover: a comparative study with emphasis on the US and Japan, Princeton University.

[9] Brown, C. et al (1997), Work and Pay in the United States and Japan, oxford University Press.

[10] Brunello, G. (1996), Equilibrium Unemployment with Internal Labor Markets, Economica, 63, 19-35.

[11] Brunello, G. and Medio, A. (1996), A Job Competition Model of Workplace Training and Education, FEEM Working Paper no. 75-96.

[12] Burda, M. and Wyplosz, C. (1993), Gross Worker and Job Flows in Europe, CEPR Discussion Paper n. 868.

[13] European Commission (1992), Employment in Europe, Bruxelles.

[14] Franz, W, and Soskice, D., (1995), The German Apprenticeship System, in Buttler,F., Franz,W., Schettkat, R. and Soskice, D., Institutional Frameworks and labor market performance, Routledge.

[15] Freeman, R. (1995), Does it Fit? Drawing Lessons from Differing Labor Practices, CEP Discussion Paper n.230, LSE.

[16] Laing, D., Palivos, T. and Wang, P. (1995), Learning, Matching and Growth, The Review of Economic Studies, 62, 115-129. 
[17] Layard, R., Nickell, S. and Jackman, R. (1991), Unemployment, Blackwell.

[18] Lynch, L. (1993), The Economics of Youth Training in the United States, The Economic Journal, 103, 1292-1302.

[19] Lynch, L. (1994), Training and the Private Sector, The University of Chicago Press.

[20] Malcolmson, J. (1997), Contracts, hold ups and labor markets, in Journal of Economic Literature, 35, 1916-57.

[21] OECD (1991), Enterprise-Related Training, Employment Outlook, Paris.

[22] OECD (1993), Employment Outlook, Paris.

[23] OECD (1994), The Jobs Study, Paris.

[24] OECD (1995), Education at a Glance, Paris.

[25] Pissarides, C. (1990), Equilibrium Unemployment Theory, Blackwell, Oxford

[26] Redding,S. (1996), The Low Skill- Low Quality Trap: Strategic Complementarities between Human Capital and R\&D, The Economic Journal, $106,458-470$.

[27] Rosen, S. (1976), A Theory of Life Earnings, Journal of Political Economy, 84,4, S44-S67.

[28] Saint Paul, G. (1996), Dual Labor Markets, MIT Press, Cambridge MA.

[29] Sicherman, N. (1991), Overeducation in the Labor Market, Journal of Labor Economics, 9, 2, 101-122.

[30] Snower, D. (1994), The Low-Skill, Bad-Job Trap, Discussion Paper n.14, Birbeck College, London.

[31] Stevens, M. (1994), An Investiment Model for the Supply of Training by Employers, The Economic Journal, 104, 556-570.

[32] Thurow, L. (1975), Generating Inequality, McMillan, London. 